\title{
RUWATAN
}

\section{dalam Masyarakat Jawa}

\section{Rukiyah}

\section{Jurusan Sastra Indonesia Fakultas Sastra Universitas Diponegoro}

\begin{abstract}
Ruwatan is a Javanese traditional ceremony. This paper discusses the basic reason of ruwatan, who should need ruwatan, what elements are present in ruwatan, and how ruwatan ceremonial ordinances. Descriptive analysis answers that ruwatan held as a means to escape from the disaster that purported to be carried in a ruwatan holder. The basis of holding ruwatan is a myth that gave birth Batara Kala who would prey on children of Sukerta.
\end{abstract}

Key words: ceremony, Ruwatan, Batara Kala, Javanese belief

\section{Pendahuluan}

\section{1. Latar Belakang}

Setiap manusia mendambakan keselamatan, kebahagiaan, dan kesejahteraan jasmani maupun rohani di dalam kehidupannya. Salah satu cara yang dilakukan oleh masyarakat Jawa untuk mencapai keinginan tersebut adalah mengadakan upacara sepanjang lingkaran hidup. Upacara lingkaran hidup dilakukan sejak manusia dalam kandungan hingga meninggal dunia. Koentjaraningrat (1984: 349-377) mengemukakan berbagai macam upacara yang dilakukan orang Jawa berkaitan dengan lingkaran hidup. Upacara yang diperuntukkan bagi manusia yang belum lahir adalah tingkepan atau mitoni. Setelah manusia dilahirkan, bentuk upacara yang dilakukan meliputi brokohan, sepasaran, puputan, selapanan, tedhak siten, sunatan, perkawinan, dan 
ruwatan. Adapun upacara bagi orang yang sudah meninggal dunia, antara lain mitung dina, nyatus, pendhak sepisan, pendhak pindho, dan nyewu.

Salah satu upacara lingkaran hidup yang sampai sekarang masih dilaksanakan oleh masyarakat Jawa adalah ruwatan. Upacara ini dilaksanakan sebagai sarana untuk melepaskan diri dari bencana yang akan disandang selama hidupnya. Pada tata upacara ruwatan, terlihat jelas adanya situasi dan kondisi sakral, seperti pembacaan mantra-mantra oleh dalang, sebagai pemimpin upacara, disertai dengan sesajian dan pembakaran dupa, serta bunyi-bunyian dari gamelan yang memungkinkan timbulnya daya magi. Pada dasarnya pelaksanaan upacara ruwatan adalah salah satu usaha untuk mengadakan kontak dengan dunia supranatural, dunia gaib, sehinggga para penghuninya, yaitu roh-roh halus dapat dipanggil untuk keperluan dan tujuan tertentu.

Ruwatan merupakan salah satu upacara adat Jawa yang menarik untuk dikaji terkait dengan konsep yang mendasari dilaksanakannya dan tata cara pelaksanaannya. Tulisan ini mengungkap tentang konsep dasar upacara ruwatan, siapa saja yang harus diruwat, unsur apa saja yang harus ada dalam upacara ruwatan, dan bagaimana tata cara ruwatan.

\section{2. Landasan Teori dan Metode Pengumpulan Data}

\section{2. 1. Landasan Teori}

Pola pemikiran masyarakat Jawa mengenai dunia kosmis, magis, dan klasifikatoris termasuk ke dalam sistem religi, yang terwujud dalam tata upacara ruwatan. Berbicara tentang ruwatan tidak dapat dilepaskan dari

konteks kebudayaan karena ruwatan merupakan bagian dari tujuh unsur kebudayaan yang disebut cultural universal yang terdiri dari (1) bahasa, (2) sistem pengetahuan, (3) organisasi sosial, (4) sistem peralatan hidup dan teknologi, (5) sistem mata pencaharian, (6) sistem religi, dan (7) kesenian. (Koentjaraningrat, 1990: 203-204). 
Menurut Koentjaraningrat sistem religi mengandung empat komponen pokok atau utama yang harus ada dalam rangkaian upacara, yaitu (1) tempat pelaksanaan upacara, (2) saat atau waktu pelaksanaaan upacara, (3) bendabenda pusaka dan perlengkapan alat-alat upacara, dan (4) orang-orang yang bertindak sebagai pelaksana upacara. Lebih lanjut dijelaskan bahwa selain empat komponen utama tersebut dalam upacara adat terdapat juga kombinasi dari berbagai unsur, seperti berdoa, bersujud, bersaji, berkorban, makan bersama, menari, menyanyi, berprosesi, berseni, berpuasa, bertapa, dan bersemedi (Koentjaraningrat, 1985: 240).

\section{2. 2. Metode Pengumpulan dan Analisis Data}

Pengumpulan data tentang ruwatan dilakukan dengan menggunakan studi pustaka, observasi, dan wawancara. Observasi dilakukan dengan mengamati secara langsung pelaksanaan upacara ruwatan yang diadakan oleh keluarga Bapak Mutarom, sebagai informan kunci, pada saat meruwat anaknya. Penulis melakukan wawancara dengan pelaku ruwatan, dengan teknik wawancara yang tak tersruktur, yaitu wawancara yang dilakukan dengan mengajukan pertanyaan kepada responden sesuai dengan kebutuhan penelitian, serta memberikan kebebasan seluas-luasnya pada informan untuk mengeluarkan pandangan, perasaan, pikiran, keyakinan, dan kepercayaannya tanpa diatur oleh peneliti. Data yang didapat dari studi pustaka, observasi, dan wawancara, dianalisis dengan menggunakan metode kualitatif yang bersifat deskriptif analisis.

\section{Arti dan Tujuan Ruwatan}

Ruwatan berasal dari kata ruwat yang berarti 1) luar saka panenung (wewujudan sing salah kedaden); 2) luar saka ing beban lan paukumaning dewa; ruwatan berarti slametan (Poerwadarminta, 1939: 534). Tujuan diadakannya ruwatan adalah agar manusia selamat, terhindar dari bahaya, 
kesialan, bebas dari kutukan serta pengaruh jahat sehingga dapat hidup dengan tentram.

Konsep yang mendasari adanya ruwatan adalah mitos kamasalah atau salah kedaden sehingga melahirkan Batara Kala, yang merupakan akibat ulah asmara yang tidak pada tempatnya, yang melanggar etika pembabaran wiji dadi yang dilakukan oleh Dewa tertinggi (Batara Guru).

Cerita bermula ketika Batara Guru yang sedang berdua dengan Dewi Uma naik lembu Andini dan bercengkerama keliling dunia di suatu senja yang indah. Pada saat itu Batara Guru ingin memadu asmara, dan Dewi Uma menolak; namun kama atau "air benih kehidupan" sudah terlanjur ke luar dan jatuh di samudera. Kama yang ke luar tidak pada tempatnya karena nafsu yang sudah tak terkendali ini disebut kama salah, yang kemudian menjadi raksasa sebesar gunung.

Sesampainya di kahyangan, Batara Guru mendengar adanya huru-hara di bumi, maka diperintahlah para dewa untuk mencari penyebab huru-hara tersebut. Ternyata huru-hara itu disebabkan oleh ulah seorang raksasa yang mencari ayahnya dan minta makan. Huru-hara itu berakhir setelah Batara Guru mengakui raksasa itu sebagai anaknya dan memberinya nama Batara Kala, serta memberi jatah makan berupa anak atau orang sukerta.

Jatah makan yang diberikan kepada Batara Kala ternyata terlalu banyak dan dapat berakibat musnahnya manusia di dunia. Menyadari kekeliruannya, Batara Guru kemudian memerintahkan Batara Wisnu beserta para dewata untuk turun ke dunia menyelamatkan umat manusia. Batara Wisnu bertindak sebagai dalang Kandhabuwana dan para dewata sebagai pengrawit meruwat manusia yang menjadi jatah makan Batara Kala.

Mitos inilah yang menjadi dasar adanya ruwatan yang sampai sekarang masih dilaksanakan oleh masyarakat Jawa agar anak atau orang yang mereka cintai yang tergolong anak atau orang sukerta tidak dimakan oleh Batara Kala.

\section{Orang-orang yang Harus Diruwat}


Pada bagian sebelumnya sudah disebutkan bahwa makanan Batara Kala adalah orang sukerta. Agar tidak menjadi santapan Batara kala orang sukerta harus diruwat. Sukerta artinya arubiru (Poerwadarminta, 1939: 570), yang berarti rerusuh, pangganggu gawe (Poerwadarminta, 1939: 19). Berdasarkan arti kata tersebut, dapat dikatakan orang sukerta adalah orang yang menyebabkan kekacauan. Siapa sajakah yang tergolong orang sukerta? Ada beberapa pendapat mengenai siapa saja yang tergolong orang sukerta, namun dari beberapa pendapat tersebut ada beberapa yang sering disebut, sebagai berikut.

(1) Anak tunggal, laki-laki maupun perempuan (ontang-anting);

(2) anak dua bersaudara, keduanya laki-laki (uger-uger lawang);

(3) anak dua bersaudara, keduanya perempuan (kembang sepasang);

(4) anak dua bersaudara, laki-laki dan perempuan (kedhana-kedhini);

(5) anak perempuan dengan seorang kakak laki-laki dan seorang adik laki-laki (sendhang kapit pancuran);

(6) anak laki-laki dengan seorang kakak perempuan dan seorang adik perempuan (pancuran kapit sendhang);

(7) anak lima bersaudara semuanya laki-laki (pendawa);

(8) anak lima bersaudara semuanya perempuan (pendawi atau putra pandawa padangan);

(9) anak kembar sejenis maupun tidak sejenis (kembar);

(10) menjatuhkan atau merubuhkan alat masak dandang ketika sedang menanak nasi (ngrubuhake dandang); dan

(11) memecahkan batu alas atau batu pelindasnya (wong nugelake pipisan utawa gandik).

\section{Unsur-Unsur Ruwatan}

Unsur-unsur yang terdapat dalam acara ruwatan meliputi sebagai berikut. 
4. 1. Anak atau orang yang akan diruwat, yaitu anak sukerta. Anakanak yang harus diruwat adalah mereka yang menurut keyakinan merupakan anak yang kotor, aib, dosa, yang menyebabkan kemalangan bagi dirinya maupun keluarga dan lingkungan, yang menyebabkan adanya gangguan dari makhluk gaib terhadap dirinya.

4. 2. Dalang, merupakan tokoh sentral dan penting dalam upacara ruwatan. Dalang ruwatan biasanya dalang yang khusus meruwat; dia harus dalang turunan, artinya ketrampilannya mendalang diperoleh secara turuntemurun. Dalam upacara ruwatan dalang berfungsi sebagai penghubung antara dunia yang bersifat nyata dengan dunia supranatural.

4. 3. Perlengkapan pergelaran wayang purwa dengan lakon "Murwa Kala," yang terdiri dari a) gamelan Jawa, b) wayang kulit satu kotak, lengkap, c) kelir (kain), d) blencong (lampu minyak). Wayang adalah sarana ideal untuk mengadakan upacara ruwatan karena wayang (wayang purwa) dapat menyingkirkan marabahaya, sebagaimana dikemukakan oleh G.A.J. Hazeau, bahwa dengan wayang dimaksudkan dapat menolak bala atau sesuatu yang buruk, misalnya menolak malapetaka yang akan tiba atau kesengsaraan yang diderita oleh seseorang karena perbuatan-perbuatan yang tersimpul dalam tamsil, seperti orang yang memecahkan gandik, orang merobohkan dandang periuk nasi (Hazeau, 1979: 68).

4. 4. Sesajen, yaitu segala sesuatu yang dapat berupa makanan atau benda-benda lain yang khusus diperuntukkan bagi makhluk halus. Sesajen merupakan srana yang dipergunakan sebagai sarana untuk mengadakan hubungan dengan penghuni alam lain di luar alam manusia. Karena alam lain tersebut bersifat "halus," maka sesajen tersebut konon hanya disantap bau atau aromanya saja. Seperti dikemukakan oleh Hazeau bahwa menurut kepercayaan, orang yang sedang menyajikan sesajen sesungguhnya bukan wujud lahiriah makanan yang disajikannya itu yang disantap, melainkan baunya belaka 
(Hazeau, 1979: 71). Sesajen dalam upacara ruwatan menurut Kamajaya (1992: 48-49) terdiri dari sebagai berikut.

(1) Tuwuhan, yaitu sepasang pohon pisang raja lengkap dengan daun, pelepah, dan buah yang sudah menguning, cengkir gading atau kelapa muda, tebu wulung dengan daunnya, daun beringin, daun elo, daun apa-apa, daun maja, daun kara, alang-alang, daun dadap serep, daun kluwih; daun-daunan tersebut diikat menjadi satu. Tuwuhan, cengkir gading, serta daun-daunan dipasang di kiri dan kanan kelir. Tuwuhan artinya yang tumbuh, jadi merupakan lambang kehidupan. Pisang bermakna pepindhaning ngagesang, yang lengkap dan utuh kadang masih dengan tuntutnya (bunganya), yang berarti sebagai tuntutan atau pilihan hidup dan kehidupan yang baik, berhasil, tumbuh, berkembang, berbunga, dan berbuah, bermanfaat bagi kehidupan sesama. Cengkir gading (kencenging pikir) berarti kekuatan pikiran yang jernih, dipadu dengan tebu wulung: tebu (anteping kalbu) berarti ketetapan hati. Perpaduan perasaan hati dan akal pikiran jernih cemerlang akan memecahkan persoalan dengan baik. Daun elo, daun maja, daun apa-apa, daun kara, alang-alang, daun dhadhap serep diikat menjadi satu melambangkan keburukan diikat, dikendalikan, disingkirkan sedangkan yang baik diambil dan dimanfaatkan. Daun kluwih dimaknai sebagai harapan untuk dapat melebihi yang ada di sekitarnya dalam konotasi yang baik, sedangkan daun beringin melambangkan pengayom atau pelindung.

(2). Kembar mayang (terbuat dari daun puring, andhong, kenikir, patramanggala), bunga setaman yang diletakkan di bokor.

(3) Arang yang diletakkan di dalam anglo dan dinyalakan untuk membakar kemenyan selama pertunjukan wayang berlangsung.

(4) Kain mori putih sepanjang 3 (tiga) meter dibentangkan di bawah debog (batang pohon pisang) yang digunakan untuk menancapkan anak wayang; di atas kain mori ditaburi bunga mawar. 
(5) Sinjang (kain batik) yang masih baru poleng, gadhung mlathi, bango tulak, tuluh watu, dringin, pandhan binethot; sinjang merupakan simbol dalam kehidupan relijius.

(6) Makanan, berupa (a) nasi golong dengan aneka gorengan, pindang kluwih, pecel ayam, dan sayur menir; (b) nasi wuduk dengan lalapan, timun, cabai merah dan hijau, brambang, dan kedelai hitam; (c) nasi kuning dengan dadar telur dan srundeng; (d) macam-macam bubur atau jenang seperti bubur merah, bubur putih, bubur kaleh, bubur baro-baro (bubur yang bermacammacam); (e) jajan pasar seperti pisang raja, jambu, salak, rujakan.

4. 5. Peralatan pertanian, seperti garu, wluku, pacul, linggis, parang, pisau, sabit, caping, pecut, dan cengkrong; peralatan pertanian merupakan sarana untuk mengolah tanah sebagai lahan kehidupan tumbuh-tumbuhan.

4. 6. Peralatan dapur, seperti dandang, kendhil, kuali, genthong, enthong, wajan pengaron, kukusan, tampah, irig, siwur, dan irus; peralatan dapur merupakan sarana untuk mengolah hasil pertanian.

4. 7. Ternak, unggas: sapi, kerbau, kambing, angsa, ayam, burung perkutut, burung merpati, dan itik; ternak dan unggas menjadi sarana dan bahan untuk kelanjutan hidup.

4. 8. Peralatan tidur: tikar, bantal, seprei; peralatan tidur merupakan sarana keseimbangan daya tahan tubuh.

4. 9. Hasil pertanian, meliputi padi, jagung, kacang hijau, kelapa, pisang, buah-buahan, waluh, semangka, ubi, gembili, dan gadhung; makanan dan hasil pertanian merupakan sumber tenaga untuk menjalani hidup di dunia.

\section{10. Jarum dan benang hitam dan putih.}

\section{11. Kaca kecil.}

\section{12. Kendi berisi air.}

Sesaji tersebut telah memanifestasikan hakikat hidup dan kehidupan manusia dan alam serta dunia gaib sebagai satu kesatuan solidaritas kehidupan. Manusia mempersembahkan semua hasil bumi yang diolahnya kepada dewa 
sebagai penguasa dengan harapan Batara Kala akan melepaskan jatah makannya demi keselarasan dan keseimbangan kosmos.

4. 13. Mantra, merupakan unsur magis dalam upacara ruwatan. Pada saat dalang membacakan mantra hadirin tidak diperkenankan merokok, makan, dan minum, dan wanita hamil harus meninggalkan tempat berlangsungnya ruwatan. Mantra yang dibacakan dalam upacara ruwatan bervariasi.

\section{Tata Cara Ruwatan}

Upacara ruwatan diawali dengan pagelaran wayang purwa dengan cerita Murwakala pada pukul 09.00-13.00 dengan dalang yang sudah berpengalaman meruwat. Dalang dalam upacara ruwatan bertanggung jawab penuh atas pelaksanaan pagelaran wayang maupun penyelenggaraan ruwatan secara spiritual. Sebelum meruwat dalang ruwatan biasanya melakukan laku atau nglakoni sebagai syarat agar pelaksanaan ruwatan berjalan lancar, tanpa ada halangan. Ia melakukan puasa, tidak melakukan hubungan badan dengan wanita selama 100 (seratus) hari atau minimal 40 (empat puluh) hari, bertapa bisu, dalam arti tidak berbicara sejak bangun tidur menjelang fajar hingga saat matahari terbit, dan mengheningkan cipta mohon keselamatan lahir batin. Tidur sekali dalam sehari semalam, artinya jika sudah bangun dari tidur dia tidak boleh tidur lagi sejak menjelang fajar sampai pukul 22.00. Sebelum tidur dan setelah bangun harus mandi keramas, mengguyur seluruh badan, kemudian jalan-jalan sekuatnya.

Setelah pertunjukan wayang berakhir dilanjutkan dengan siraman, yaitu memandikan anak atau orang yang diruwat dengan menggunakan air bunga setaman dan wewangian. Siraman dilaksanakan dengan tujuan menghilangkan aib, nasib jelek yang membayangi hidupnya. Siraman dan percikan air suci membuat semua noda dan kotoran larut dari badan sehingga jiwa dan raganya bersih. Dengan fisik dan jiwa baru yang bersih anak sukerta yang diruwat akan menjadi orang baru yang siap menghadapi tantangan dalam hidup barunya. 
Potong rambut merupakan rangkaian tata upacara selanjutnya. Upacara ini dilakukan untuk membuang sesuker, kotoran fisik manusia. Rambut dan kuku termasuk benda magi yang dapat dipakai sebagai sarana magi hitam untuk mencelakakan seseorang. Potongan rambut akan ditanam atau dilarung dengan beras sebanyak 4 (empat) kg, uang sejumlah harga 1 (satu) gram emas, ayam, sandal dari kayu (teklek), benang lawe satu gulung, telur ayam yang baru saja ke luar (belum sampai satu hari), gula jawa sepasang (setangkep), gula pasir 1 (satu) kg, dan kelapa satu butir, serta sedikit darah yang diambil dengan cara menusukkan duri pada jari atau bagian tubuh yang lain. Darah yang ke luar kemudian diusap dengan kapas. Kapas dan duri inilah yang disertakan dalam benda-benda yang dilarung atau ditanam bersama potongan rambut. Pada saat menanam atau melarung benda-benda tersebut sambil mengucapkan "ingsun ora mbuang klapa lan isine, ananging mbuang apa kang ndadekake apesing awakku" (saya tidak membuang kelapa dan isinya, melainkan membuang apa yang membuat celaka badanku). Maksud dari menanam atau melarung adalah mengubur atau menghayutkan semua kotoran, aib, noda yang membebani hidup anak sukerta selama ini.

Malam hari setelah upacara ruwatan diadakan tirakatan yang dilakukan oleh seluruh keluarga. Orang tua anak yang diruwat, anak yang diruwat tidak tidur semalaman memohon kepada Tuhan untuk keselamatan dan kehidupan yang lebih baik di masa mendatang.

\section{Simpulan}

Ruwatan merupakan upacara dalam sistem religi yang dipercayai sebagai sarana melepaskan, menghalau, maupun membebaskan seseorang dari ancaman mara bahaya yang disebabkan oleh suatu peristiwa yang tersimpul dalam tamsil. Konsep yang mendasari adanya ruwatan adalah mitos kama salah yang melahirkan Batara Kala yang akan memangsa anak sukerta. Anak atau orang yang harus diruwat adalah anak atau orang yang menjadi jatah makanan Batara Kala, yaitu anak atau orang sukerta. Unsur-unsur ruwatan terdiri dari anak atau 
orang sukerta, dalang, wayang, sesajen, dan mantra. Dalang bertindak sebagai perantara antara alam manusia dengan alam supranatural atau alam gaib dengan menggunakan sarana sesajen dan mantra-mantra yang mengandung kekuatan gaib. Sedangkan tata cara ruwatan meliputi pergelaran wayang kulit dengan lakon murwakala, siraman, potong rambut, melarung atau menanam potongan rambut dan sesajen, dan diakhiri dengan tirakatan semalam suntuk.

\section{Daftar Pustaka}

Hazeau, G.A.J. 1979. Kawruh Asalipun Ringgit serta Gegepokanipun Kaliyan Agami ing Jaman Kina (dialihaksarakan oleh Sumarsana dan dialihbahasakan oleh Hardjana HP). Jakarta: Departemen P dan K Penerbitan Buku Bacaan dan Sastra Indonesia dan Daerah.

Kamajaya, 1992. Ruwatan Murwakala: Suatu Pedoman. Yogyakarta: Yayasan Centhini.

Koentjaraningrat. 1984. Kebudayaan Jawa. Jakarta: PN Balai Pustaka. . 1985.Beberapa Pokok Antropologi Sosial. Jakarta: Dian

Rakyat. 1990. Pengantar Ilmu Antropologi. Jakarta: Rineka Cipta

Poerwadarminta. W.J.S. 1939. Baoesastra Djawa. Batavia: J.B.Wolters Uitgevers-Maatschappij N.V. Groningen. 